\title{
Risk-sensitive foraging does not explain condition-dependent choices in settling reef fish larvae
}

\author{
Emma E Bogdan ${ }^{1}$, Andrea L Dingeldein ${ }^{1}$, Deirdre L Bertrand ${ }^{1}$, Will White ${ }^{\text {Corresp. } 2}$ \\ ${ }^{1}$ Department of Biology and Marine Biology, University of North Carolina at Wilmington, Wilmington, North Carolina, United States \\ 2 Department of Fisheries and Wildlife, Coastal Oregon Marine Experiment Station, Oregon State University, Newport, Oregon, USA \\ Corresponding Author: Will White \\ Email address: will.white@oregonstate.edu
}

The transition from the planktonic larval to the benthic adult stage in reef fishes is perilous, and involves decisions about habitat selection and group membership. These decisions are consequential because they are essentially permanent (many fish rarely leave their initial settlement habitat, at least for the first several days or weeks). In one common Caribbean reef fish, the bluehead wrasse (Thalassoma bifasciatum), settling larvae either join groups or remain solitary. Grouped fish have lower mortality rates but slightly slower growth rates, and fish that are smaller at the time of settlement are less likely to join groups. We hypothesized that the decision of smaller (i.e., lower condition) fish to remain solitary could be explained by risk-sensitive foraging: with less competition, solitary fish may have higher variance in foraging success, so that there is a chance of a high payoff (outweighing the increased mortality risk) despite the lack of a large difference in the average outcome. We tested this by comparing the mean, standard deviation, and maximum number of a) prey items in stomach contents and b) post-settlement growth rates (from otolith measurements) of solitary and grouped fish during two settlement pulses on St. Croix, U.S. Virgin Islands. However, we did not find evidence to support our hypothesis, nor any evidence to support the earlier finding that fish in groups have lower average growth rates. Thus we must consider alternative explanations for the tendency of smaller fish to remain solitary, such as the likely costs of searching for and joining groups at the time of settlement. This study reinforces the value of larval and juvenile fish as a testbed for behavioral decisionmaking, because their recent growth history is recorded in their otoliths. 


\section{Risk-sensitive foraging does not explain condition-dependent}

\section{3 choices in settling reef fish larvae}

4

5

6

7

\section{8}

9

10

11

12

13

14

15

16

17

18

19

20

21

22

23

24

25

26

29

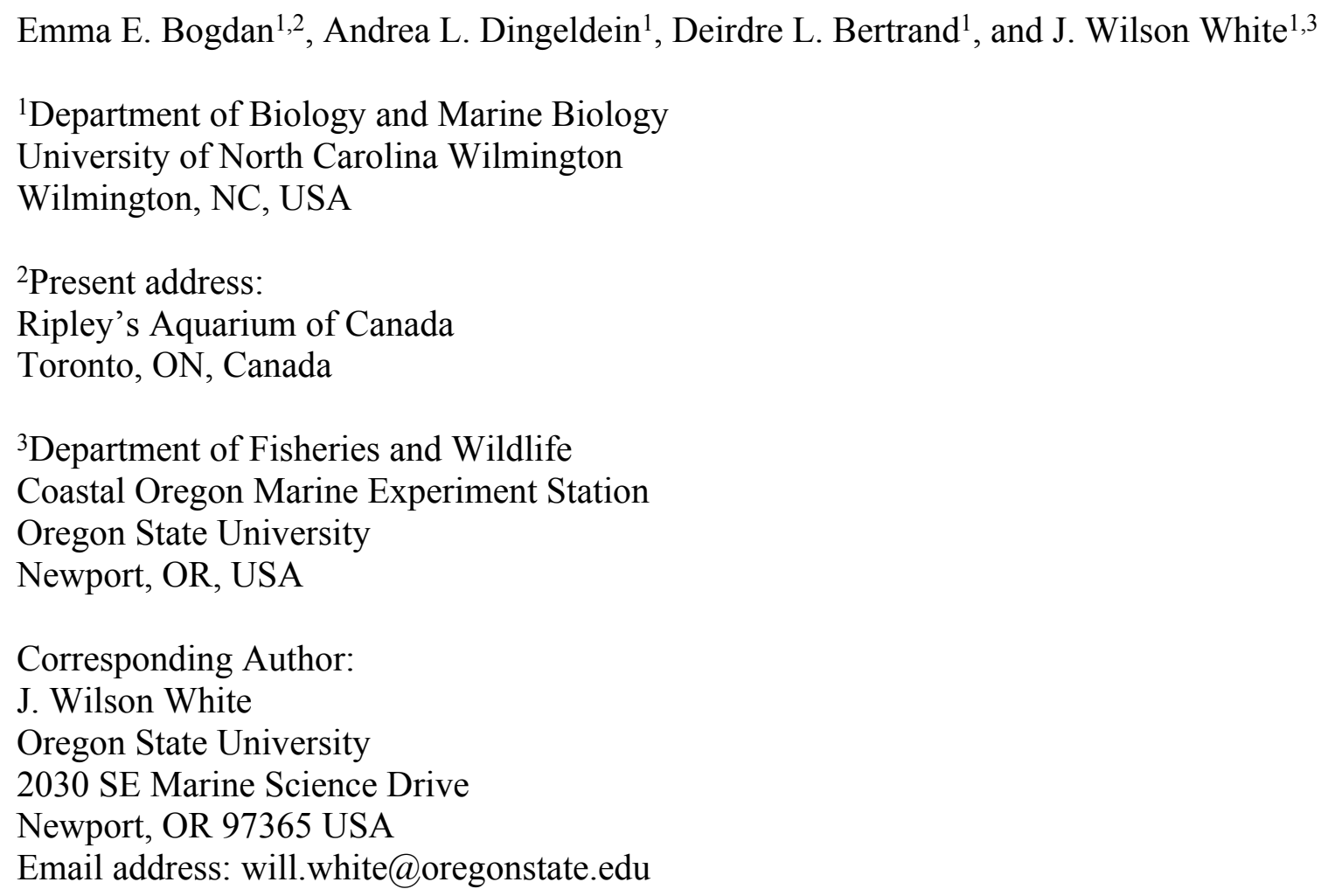


30

31

32

\section{Abstract}

The transition from the planktonic larval to the benthic adult stage in reef fishes is perilous, and involves decisions about habitat selection and group membership. These decisions are consequential because they are essentially permanent (many fish rarely leave their initial settlement habitat, at least for the first several days or weeks). In one common Caribbean reef fish, the bluehead wrasse (Thalassoma bifasciatum), settling larvae either join groups or remain solitary. Grouped fish have lower mortality rates but slightly slower growth rates, and fish that are smaller at the time of settlement are less likely to join groups. We hypothesized that the decision of smaller (i.e., lower condition) fish to remain solitary could be explained by risksensitive foraging: with less competition, solitary fish may have higher variance in foraging success, so that there is a chance of a high payoff (outweighing the increased mortality risk) despite the lack of a large difference in the average outcome. We tested this by comparing the mean, standard deviation, and maximum number of a) prey items in stomach contents and b) post-settlement growth rates (from otolith measurements) of solitary and grouped fish during two settlement pulses on St. Croix, U.S. Virgin Islands. However, we did not find evidence to support our hypothesis, nor any evidence to support the earlier finding that fish in groups have lower average growth rates. Thus, we must consider alternative explanations for the tendency of smaller fish to remain solitary, such as the likely costs of searching for and joining groups at the time of settlement. This study reinforces the value of larval and juvenile fish as a testbed for behavioral decision-making, because their recent growth history is recorded in their otoliths. 


\section{Introduction}

54

55

56

57

58

When making choices that affect fitness in a stochastic environment, animals often account for both the average fitness payoff for different alternatives as well as the relative variance associated with those payoffs (Caraco et al. 1980, Barkan 1990, Kacelnik \& Bateson 1996, Houston \& McNamara 1999, Kacelnik \& El Mouden 2013). For example, in the classic original experiment, Caraco et al. (1980) showed that well-fed yellow-eye juncos (Junco phaeonotus) were risk-averse in their food preferences, preferring feeding stations with a lower variance in the amount of food delivered, regardless of the average amount. However, juncos on a poorer diet were risk-prone, choosing higher-variance feeding stations. This behavior can be explained by the 'budget rule': if an animal's energy budget is sufficient to meet immediate needs (e.g., overnight survival), it will be risk-averse, minimizing the chance of low or zero payoffs. If, however, the energy budget is lacking, the animal will choose the higher-variance option (even if the mean payoff is insufficient for its needs), improving its chance at a life-saving high payoff (Stephens 1981, Smallwood 1996, Houston \& McNamara 1999). After those initial experiments in bird model systems, the concept of risk-sensitive foraging has been applied to a wide range of taxa (Kacelnik and Bateson 1996).

This simple version of the budget rule has been criticized for failing to adequately explain experimental data on foraging animals (Bateson 2002, Kacelnik \& El Mouden 2013), although more sophisticated versions of the rule produce better fits to data (Lim et al. 2016). Nonetheless, there is a general expectation that animal behaviors reflect differences in the variance of payoffs from different choices. For example, some spiders switch between sit-and-wait and mobile hunting strategies depending on the variance in prey encounter rates (Caraco \& Gillespie 1986, Gillespie \& Caraco 1987; but see Smallwood 1993 for an alternative explanation). In common 
76 eiders, Somateria mollissima, birds in poor energetic condition joined smaller flocks and foraged

77 in habitats with less-preferred prey but a more variable energetic return, apparently minimizing

78 competition and gaining the possibility of a bigger payoff in prey collection (Guillemette et al.

79 1992).

Many benthic marine organisms face a period of crucial and irreversible decision-making

when they make the transition from a highly dispersive planktonic larval stage to a less mobile, benthic adult stage, often with home ranges on the scale of meters or even centimeters (Doyle 1975, Stamps et al. 2005). The adult habitat selected by the settling larva will have long-term fitness consequences, leading to strong selective pressure for the evolution of adaptive settlement behaviors. For example, larval barnacles use chemical cues from intertidal organisms that share a similar range of environmental tolerances, allowing them to select appropriate locations for settlement in the intertidal (Raimondi 1988). Larval coral reef fish also respond to chemical cues, improving their chance of settling in higher-quality habitats (Dixson 2011, Dixson et al. 2014) and some species also avoid locations that are already occupied by competitors or older conspecifics in order to avoid competition (Stier \& Osenberg 2010). All of these examples describe scenarios in which larvae respond to differences in the mean payoff between settlement sites. In this paper, we investigated whether larvae also respond to the variance in fitness payoffs when making settlement decisions.

In addition to the decisions about settlement habitat that other coral reef fishes make, settling larvae of the bluehead wrasse, Thalassoma bifasciatum, also face a choice about social group membership. Bluehead wrasse are one of the most common fish on Caribbean reefs, and adults are highly mobile, swimming rapidly around the reef in loose aggregations. This species is also well-known as a model system for investigations of the evolution and behavioral ecology of 
99

100

101

102

103

104

105

106

107

108

109

110

111

112

113

114

115

116

117

118

119

120

121

mating systems and protogynous sex change (Warner 2001). Here we focus instead on the behavioral ecology of the early juvenile stages. At the time of settlement from the plankton, larval bluehead wrasse bury themselves in the reef sediment for approximately 3-5 days while they metamorphose (Victor 1982). When they emerge, juvenile wrasse are highly site-attached for the first week of their life on the reef, staying within tens of $\mathrm{cm}$ from a shelter crevice while cautiously feeding on zooplankton in the water column. At this time, juvenile bluehead wrasse are either solitary or form small groups of up to twenty. Fish that are larger at the time of settlement are more likely to be found in groups, and per-capita mortality declines with increasing group size (White \& Warner 2007a, Dingeldein \& White 2016). White \& Warner (2007b) showed that fish in groups spend considerably more time foraging than solitary fish, but have somewhat slower post-settlement growth rates, likely due to competition. Fish vary in size and age within groups (although all are less than approximately 7 post-emergence days old), and aggressive 'chasing' encounters are common among groupmates (White and Warner 2007b).

Bluehead wrasse begin to become less site-attached and leave these groups after approximately one week, changing behaviors to associate with mobile shoals of older, larger conspecifics. However, that first week on the reef is a window of very high mortality, and a time when behavioral decisions alter mortality risk considerably.

\section{These observations of behavior and growth suggest that smaller fish trade the safety of} group membership for the opportunity for a faster growth rate (White \& Warner 2007a, 2007b, Dingeldein \& White 2016). Faster growth is a metric of (eventual) fitness in small immature fish. This is because many coral reef predators are gape-limited (they can only consume things smaller than their mouth opening) so as small fish grow, fewer predators are able to consume them. Thus faster-growing fish spend less time in vulnerable size classes, conferring greater 
122 survival and a better chance of reaching reproductive age (Miller et al. 1988, Houde 1989).

123 However, the negative relationship between growth rate and group size reported by White \&

124 Warner (2007b) was small, and perhaps not biologically significant (though statistically

125 significant, the $r^{2}$ was only 0.09 ). Therefore, we investigated whether the group-joining decision

126 of juvenile bluehead wrasse was risk-sensitive, and a response to the variance in fitness

127 outcomes rather than (or perhaps in addition to) the mean.

128 We hypothesized that small fish may be more likely to remain solitary because of the

129 potential for higher prey capture rates and higher growth rates. To test this hypothesis, we re-

130 analyzed the dataset collected by Dingeldein \& White (2016), who found an effect of size-at-

131 settlement on the decision to join groups, but did not examine the post-settlement growth rates of

132 the fish they collected. We analyzed the post-settlement growth rates (estimated from otolith

133 growth rings) to test for differences between solitary and grouped fish in the a) mean and b)

134 variance of both gut fullness and growth rates. We anticipated that while the means would not

135 differ (or differ only slightly), solitary fish would exhibit higher variances in growth, indicating

136 that remaining solitary is a risk-prone strategy for small juvenile wrasse.

138 Materials \& Methods

139 The samples used in this study were collected by Dingeldein \& White (2016), and

140 additional details of collection are provided there. Recently settled juvenile bluehead wrasse

141 were collected using hand nets and clove oil anesthetic from three sites on the northwest shore of

142 St. Croix, USVI (Fig. S1). Bluehead wrasse settle to the reef in approximately week-long pulses

143 following a new moon (Caselle \& Warner 1996); collections for this study occurred during

144 settlement pulses in July and August of 2012. Dingeldein \& White (2016) described collecting 
145 two sets of fish: zero-day collections, in which larvae settling to a transect were collected on

146 their first day after emergence onto the reef, and additional collections in which entire groups

147 and solitary fish were selected haphazardly for collection after they had been on the reef for 1-4

148 days (age could be ensured because the transects were cleared of all fish on day 0, and tagging

149 has shown that fish do not move between shelter crevices after emergence; White and Warner

150 2007a). We used the latter set of collections to examine patterns of post-settlement growth. Fish

151 were preserved immediately after each dive in $75 \%$ ethanol.

152 All samples were collected following the current laws of the United States Virgin Islands

153 (USVI); fieldwork was performed in accordance with the USVI Department of Planning and

154 Natural Resources (Permit No. STX-041012) and with approval of the University of North

155 Carolina Wilmington's Institutional Animal Care and Use Committee (Protocol A1011-009), in

156 compliance with the U.S. National Research Council's Guide for the Care and Use of Laboratory

157 Animals.

158

159

Planktonic resource quantification

160 To quantify the availability of the bluehead wrasses' planktonic prey, we conducted plankton

161 tows on SCUBA at each site, swimming approximately $0.5 \mathrm{~m}$ over the reef, perpendicular to the

162 transects on which fish were collected. The width of the transect area $(\sim 30 \mathrm{~m})$ was sampled twice

163 by beginning at the first transect, swimming out to the last, and returning to the beginning.

164 Plankton tows were conducted on the same days that fish were collected (except for the first of

165 four days of sampling in both July and August at the Butler Bay site). Plankton samples were

166 filtered through a $150 \mu \mathrm{m}$ sieve, fixed in $10 \%$ formalin, and preserved in $75 \%$ ethanol. A $1 \mathrm{~mm}^{2}$

167 gridded Sedgewick rafter cell was used to count the number of cyclopoid, harpactacoid, and 
168 calanoid copepods (and several other taxonomic groups) present in $1 \mathrm{~mL}$ of each sample. These

169 counts were scaled up to obtain abundance estimates for the entire sample. A flowmeter was

170 attached to the front of the plankton net to obtain volumetric measurements of the amount of

171 water that was sampled on each tow. This provided an estimate of the amount of available

$172 \mathrm{prey} / \mathrm{m}^{3}$ present in the water column at each given site and day.

174 Otolith analysis

175 After preservation, sagittal otoliths were extracted from each fish and placed in microscope 176 immersion oil for at least thirty days prior to improve clarity. We photographed whole otoliths at $177400 \times$ under polarized light using Leica Acquire 1.0 software (Leica Microsystems, Buffalo

178 Grove, IL, USA). We counted and measured daily otolith increment widths using ImageJ 179 software (National Institutes of Health, Bethesda, MD, USA), starting at the first visible ring and 180 counting along the longest axis (post-rostrum). In bluehead wrasse, the timing of both initial

181 larval settlement and subsequent emergence onto the reef is clearly demarked on the otolith by a 182 wide metamorphic band (Victor 1982). Therefore we were able to measure both post-settlement 183 age (number of bands after the metamorphic band) and post-settlement growth rate (the mean 184 width of post-settlement increments). Each otolith was read by the same two people and the 185 results were compared; otoliths were measured again if the post-settlement age did not agree, and 186 discarded if the readers could not reach an agreement. Data were also discarded if the 187 metamorphic band width (MBW) measurements differed by $>10 \%$. 
Stomachs of each preserved fish were dissected under 10x magnification to estimate diet

191

192

193

194

195

196

197

198

199

200

201

202

203

204

205

206

207

208

209

210

211

212

composition and stomach fullness at the time of collection. Juvenile bluehead wrasse feed continuously from approximately $30 \mathrm{~min}$. after dawn until approximately $30 \mathrm{~min}$. before dusk (J.W. White, pers. obv.), and all fish in this study were collected at least two hours after dawn and two hours before dusk to avoid crepuscular periods when the fish may have changed behavior to avoid predation risk. Diet items were classified to the lowest taxonomic level possible (usually order) and counted. Most diet items were clearly identifiable planktonic or benthic crustaceans (copepods, isopods, amphipods) and, following White and Warner (2007b), fullness was estimated as the total number of items in the stomach.

\section{Statistical analysis}

To examine differences in mean and variation in diet and post-settlement growth as a function of group size, we treated each group as an individual replicate and calculated the mean, standard deviation, and maximum number of diet items and post-settlement growth rates observed in each group. We examined the maximum because the rationale of risk-sensitive foraging is that a risky strategy affords a potentially greater fitness payoff despite a similar or lower mean fitness payoff. Solitary fish on a given reef and day were also considered to be a replicate 'group' (with a group size $=1$ ) for the purposes of calculating these statistics.

We used linear models to test for an effect of group size on mean, standard deviation, and maximum number of diet items and post-settlement growth. We performed two separate tests for each of the response variables. First, we tested for a continuous effect of group size (e.g., growth rate declines with each additional group member), so the main effect was $1 /$ (group size). Second, we tested for a simple binary difference between solitary fish and grouped fish by pooling all 
213 group sizes together. In each model we also included fixed effects of site and month to account

214 for possible spatiotemporal covariation in growth rates, as well as a fixed effect of planktonic

215 copepod density (copepods were the dominant prey item in fish stomachs; see Results). We

216 removed those effects from reported model results in a backwards stepwise fashion if their

217 effects were clearly not statistically meaningful $(p>0.2)$. For diet analyses, the planktonic

218 copepod covariate was simply the density of copepods on the day the fish was collected (only

219 fish collected on days when plankton tows were made were included in analyses with that covariate). For growth analyses, the effect of resource availability would be integrated over the

post-settlement life of the fish. Therefore, for each fish, we calculated the average copepod

222

223

224

225

226

227

228

229

230

231

232

233

234

density during the prior days the fish had been on the reef (based on the estimate of postsettlement age). We then averaged those hindcast copepod density estimates for all of the fish in each group. For diet analyses, the distributions of the mean and maximum number of diet items were asymmetrical, with long tails, so we applied a $\log (x+1)$ transformation to the data prior to analysis. All other response variables met the distributional assumptions of linear models.

Dingeldein and White (2016) had reported that fish that were larger at the time of emergence onto the reef (estimated from the otolith axis radius from the core to the outer edge of the metamorphic band) were more likely to join groups. Consequently we were concerned that size at emergence could subsequently confound detection of group effects on growth, if larger fish also tended to grow faster. We tested for this relationship and found that although it was statistically significant, due primarily to the very high sample size ( $p=0.04, \mathrm{df}=228$; Fig. S2), it had essentially no explanatory power $\left(R^{2}=0.01\right)$. We therefore decided that there was little risk of confounding effects from this factor. 
When the group size effect was found to be not statistically significant in the reduced linear

236

237

238

239

240

241

242

models, we evaluated the statistical power of the test. We did this by estimating the power of the $t$ statistic associated with the group size regression coefficient (in a two-sided test context). For these analyses, we fixed the variance of the statistic at the level observed in the test, and then calculated power for a range of sample sizes and effect sizes using the pwr package in $\mathrm{R}$ (Champely 2018).

All analyses were conducted using R 3.5.1 (R Development Core Team 2018); statistical models were constructed using the function $\mathrm{lm}$ in the basic $\mathrm{R}$ installation. Data and code are available at github.com/jwilsonwhite/bluehead_risk_sensitivity. Graphics were produced using ggplot2 (Wickham 2016).

\section{Results}

After sample processing and quality control, we were able to analyze diet and otolith data from 230 fish that were $\geq 1$ day post-settlement age (allowing a calculation of post-settlement growth rate). These fish comprised 97 individual groups of $\geq 2$ fish and 25 'groups' of solitary fish (i.e., all of the solitary fish collected from a site on a given day). Settlers ranged in age from 1-7 days post-settlement, though $95 \%$ of the individuals were $\leq 4$ days post-settlement age. The distribution of post-settlement ages in the collection did not differ between grouped and solitary individuals (Fig. S3). When calculating the mean and maximum number of diet items and growth rates, we used only data from 'groups' for which $\geq 2$ individuals were collected and successfully processed (total $n=49$; this comparison included the 'groups' of solitary fish); when calculating the standard deviation we were more conservative and only used data from groups for which $\geq 3$ individuals were available (total $n=28$, again including 'groups' of solitary fish). The latter rule 
258 necessarily excluded all pairs of fish (group size $=2$ ) but ensured that estimates of variance in

259 each group had at least $n=3$ (it did not include 'groups' of solitary fish comprised of $\geq 3$ fish

260 collected at the same site and date). The maximum number of individuals analyzed from any one

261 group was 6.

262

263

Planktonic resource availability

264

The density (number $/ \mathrm{m}^{3}$ ) of copepods sampled in plankton tows varied over two orders of magnitude between July and August across all sites, and was also variable (though less so) from day-to-day at each site (Fig. S4).

Diet

The overall diet composition of fish examined was primarily harpacticoid, cyclopoid, and calanoid copepods $(65 \%$, Fig. S5), with the remainder consisting of amphipods, isopods, ostracods, foraminifera, bivalves, and gastropods. Because copepods were both the most frequently occurring and the largest, most energy-rich prey items (cf. White and Warner 2007b), we focused our analyses on the numbers of copepods only. deviation, or maximum number of copepods in fish stomachs (Fig. 1, Table S1). For both the mean and maximum, the effect of month was not significant but did not meet the threshold for

277 stepwise removal $(0.05<p<0.2)$, so that effect is depicted in Fig. 1 as a trend towards more diet items in stomachs during the second month of sampling. For the standard deviation of stomach items, there was a significant positive effect of planktonic copepod abundance, and fish at the Northstar site had significantly fewer prey items in their stomachs. The site effect is depicted in 
281 Fig. 1b, which displays the residual standard deviation with the effect of planktonic copepods

282 removed. We obtained nearly identical results when group size was modeled as a binary factor

283 (solitary vs. grouped; Table S1, Fig. S6).

284 In general, the effects of group size were in the direction we hypothesized (e.g., greater

285 standard deviation in solitary fish) but observed effect sizes were low (e.g., 7\% lower mean and

$2864 \%$ lower standard deviation in a group of two relative to solitary fish), variation was very high

287 (Fig. 1), and the patterns were clearly not statistically meaningful ( $p>0.5$ for all group size

288 effects). We assessed our power to detect any effect, given the variation in our response variables

289 (Fig. S7). For the mean and the maximum, power would not be $>0.8$ for the observed effect size

290 even if sample size were quadrupled to over 100 groups of fish. For standard deviation,

291 increasing power to 0.8 would have required nearly quadrupling sample size to 50 groups of fish

292 (recall that we had a smaller sample size for that analysis).

293

294

Growth rate

295 There was no effect of group size (modeled as 1/[group size]) on the mean, standard

296 deviation, or maximum post-settlement growth rate (Fig. 2, Table S2). There were faster mean

297 and maximum growth rates and smaller standard deviations in growth rate in the first month of

298 sampling (despite lower planktonic resource abundances), and those effects are also depicted in

299 Fig. 2. For standard deviation in growth, the effects of site and planktonic copepod abundance

300 were not significant but did not meet the threshold for removal from the model $(0.05<p<0.2)$,

301 so the site effect is shown in Fig. $2 b$ and the response variable is shown as residuals with the

302 effect of planktonic copepod abundance removed (as in Fig. 1b). We obtained nearly identical

303 results when group size was modeled as a binary factor (solitary vs. grouped; Table S2, Fig. S8). 
effects of group size on the mean and maximum growth rate (contrary to our hypothesis), but a

307 (as we hypothesized). However, the observed effect sizes were very low (e.g., 9\% lower standard not statistically meaningful ( $p>0.25$ for all group size effects). We assessed our power to detect any effect, given the variation in our response variables (Fig. S9). For the mean and the maximum, power would not be $>0.8$ for the observed effect size even if sample size were quadrupled to over 100 groups of fish. For standard deviation, power was 0.95 at the observed effect size, variance, and sample size.

\section{Discussion}

The goal of this study was to determine whether group-joining decisions by settling fish larvae could be explained in terms of risk-sensitive behavior. Prior research had shown that fish that were larger at settlement were more likely to join groups (Dingeldein and White 2016), and that larger groups of juvenile bluehead wrasse had higher per capita survival but slower growth rates (White and Warner 2007a,b). We extended that earlier work by examining the variation in growth rates within entire groups of fish. Contrary to the trend reported by White and Warner

322 (2007b), we found no effect of group size on mean growth rate. Additionally, we did not find than do grouped fish. Thus we find no support for risk-sensitive foraging behavior as an and White 2016). 
These results suggest that bluehead wrasse that join groups at the time of settlement experience lower predation risk, despite spending more time foraging in the water column (White and Warner 2007a,b), with no apparent cost in terms of post-settlement growth. This is reinforced by our finding that there was not a relationship between post-settlement growth rate and fish size at settlement. Evidently, the latter trait (which is shaped by the larval origin and dispersal trajectory of the fish; Hamilton et al. 2008) affects the propensity to join groups (and thus mortality risk) but not post-settlement growth. Why did we not find the same pattern of mean post-settlement growth as White and Warner (2007b) did, at some of the same study sites? The most likely explanation is that negative relationship reported by White and Warner (2007b) was slight, and only detectable when variation in planktonic prey resource availability was included as a covariate. It is possible that there is temporal variation in the shape of the relationship, fluctuating between slightly negative and flat, perhaps reflecting variability in the composition of the prey field or other environmental factors that affect energetics and growth. fullness (a trend towards fewer items in the first month than the second, which matches the

342 pattern of abundance in planktonic copepods over each study reef) and post-settlement growth

343 (faster in the first month than the second). This pattern is counterintuitive, and we cannot offer a simple explanation. At the scale of individual fish, the two measures reflect different time scales: stomach contents reflect gut passage time (likely hours), while post-settlement growth integrates multiple days of resource availability. Fish collections were made on multiple days during each monthly recruitment pulse, and planktonic prey availability differed by nearly an order of magnitude at a single site from day to day, so this effect may simply reflect a few high-preyabundance days in the second month, but mean conditions that did not favor faster growth in that 
350 month. In hindsight it would have been preferable to use a sampling approach that integrated

351 copepod abundance over multiple days, as in White and Warner (2007b), but that was not

352 logistically feasible in this study.

353 When reporting results that fail to reject the null hypothesis, one must consider the

354 evidence that a Type-II error is being made. This would be a particular concern if marginal

355 increases in either effect size or sample size might have produced substantial increases in power,

356 meaning that repeating the study or increasing sample sizes would yield significant results.

357 Though we acknowledge the potential problems with post-hoc power analysis (e.g., Underwood

358 1999), in this case our power analyses suggest that in most cases the observed effect sizes were

359 simply very small relative to the variance in response variables, such that even drastic $(4 \mathrm{x})$

360 increases in sample size would not have yielded meaningfully higher power. The exception was

361 for our test of a group size effect on the standard deviation of growth rates, which had power $>$

3620.9 , also reinforcing our conclusion that we did not commit Type-II error. This is reinforced by

363 examining the data in Figs. 1 and 2: the distributions of data for every metric of both diet and

364 growth rates overlap considerably across group sizes, and differences in central tendency are

365 very small relative to the variability in the response variables. Based on that evidence, we doubt

366 that we would have detected any meaningful statistical results with greater sample size.

367 Given the lack of evidence for risk-sensitive foraging, we turn to an alternative hypothesis

368 for the tendency of smaller fish (at settlement) to remain solitary. Stamps (2006) proposed the

369 'silver spoon' hypothesis for habitat selection by dispersing juveniles. This hypothesis has two

370 parts: individuals in better condition can a) afford to be choosier during habitat selection,

371 searching longer to find better habitat, and b) better compete for a contested location, or for

372 membership in a group that might attempt to reject them. It is reasonable to see how this could 
373 apply to coral reef fish; larvae that have just settled onto the reef (or emerged from the sediment

374 post-metamorphosis, in the case of bluehead wrasse) must find a suitable shelter habitat (and

375 group) quickly, because traversing the reef during a search carries high predation risk. A larger

376 fish would have faster swimming speed and thus be able to search more area without incurring

377 additional predation exposure. We have never observed eviction from groups of juvenile

378 bluehead wrasse, so part (a) of the hypothesis appears to be more relevant than part (b), at least

379 in this species. Of course, testing such hypotheses are challenging because larval settlement

380 behaviors happen at night in unpredictable locations (and when the animals are small and nearly

381 transparent), and they are difficult to study (Holbrook and Schmitt [1997] is the only example of

382 which we are aware). However, it may be possible to examine the relative contribution of

383 instantaneous mortality risk during the search and deferred mortality risk in subsequent days

384 after habitat and group selection is complete, using a modeling approach like that of Stamps et al.

385 (2005). An additional possibility to consider is that the solitary versus grouped behaviors reflect

386 different fish personalities, particularly variation in the relative boldness of individuals (Biro and

387 Stamps 2008).

\section{Conclusions}

Larval fish are a rich testbed for examining the influences on behavioral decision-making,

391 because they carry in their otoliths a record of their past condition and growth history (Booth and

392 Beretta 2004, Grorud-Colvert and Sponaugle 2006, Dingeldein and White 2016). The details of

393 how larvae make habitat-selection and group-joining decisions continue to be a topic of

394 considerable interest and investigation (e.g., Stier and Osenberg 2010). For bluehead wrasse, we

395 had hypothesized - based on prior studies - that the likely explanation for the highly 
396 consequential decision to join a group or not was based on the potential for higher fitness payoffs

397 for solitary fish. However, our data did not provide any support for that hypothesis, and the

398 observed ratios of signal to noise suggest that this conclusion was not due to a lack of statistical

399 power. We hope that future studies may shed more light on the selective factors underlying these

400 behavioral decisions.

401

\section{Acknowledgements}

403 We thank M. Heintz for assistance in the field, and A. Orpen, J. Jaramillo, C. Brady, and L.

404 Lukas for assistance in the lab. St. Croix Ultimate Bluewater Adventures provided valuable 405 logistical support. DLB thanks her father, the late R.J. Bertrand, and her son, A. Bertrand, for 406 their enduring support. L. Tuttle and an anonymous reviewer provided helpful suggestions that 407 improved the manuscript.

408

409

410

\section{References}

411 Barkan CPL. 1990. A field test of risk-sensitive foraging in black-capped chickadees (Parus atricapillus). Ecology 71:391-400.

Biro PA, Stamps JA. 2008. Are animal personality traits linked to life-history productivity? Trends in Ecology and Evolution 23:361-368.

Booth DJ, Beretta GA. 2004. Influence of recruit condition on food competition and predation 416 risk in a coral reef fish. Oecologia 140:289-294.

417 Caraco T, Gillespie RG. 1986. Risk-sensitivity: foraging mode in an ambush predator. Ecology 418 67:1180-1185. 
419 Caraco T, Martindale S, Pulliam HR. 1980. Avian flocking in the presence of a predator. Nature $420 \quad 285: 400-401$.

421 Champley S. 2018. pwr: Basic functions for power analysis. R package version 1.2-2.

422 https://CRAN.R-project.org/package=pwr

423 Dingeldein AL, White JW. 2016. Larval traits carry over to affect post-settlement behaviour in a 424 common coral reef fish. Journal of Animal Ecology 85:903-914.

425 Dixson DL. 2011. Predation risk assessment by larval reef fishes during settlement-site selection. $426 \quad$ Coral Reefs 31:255-261.

427 Dixson DL, Abrego D, Hay ME. 2014. Chemically mediated behavior of recruiting corals and 428 fishes: a tipping point that may limit reef recovery. Science 345:892-897.

429 Doyle RW. 1975. Settlement of planktonic larvae: a theory of habitat selection in varying $430 \quad$ environments. The American Naturalist 109:113-126.

431 Gillespie RG, Caraco T. 1987. Risk-sensitive foraging strategies of two spider populations. $432 \quad$ Ecology 68:887-899.

433 Grorud-Colvert K, Sponaugle S. 2006. Influence of condition on behavior and survival potential 434 of a newly settled coral reef fish, the bluehead wrasse Thalassoma bifasciatum. Marine 435 Ecology Progress Series 327:279-288.

436 Guillemette M, Ydenberg RC, Himmelman JH. 1992. The role of energy intake rate in prey and 437 habitat selection of common eiders Somateria mollissima in winter: a risk-sensitive 438 interpretation. Journal of Animal Ecology 61:599-610.

439 Hamilton SL, Regetz J, Warner RR. 2008. Postsettlement survival linked to larval life in a 440 marine fish. Proceedings of the National Academy of Sciences USA 105:1561-1566. 
441 Holbrook SJ, Schmitt RJ. 1997. Settlement patterns and process in a coral reef damselfish: in situ 442 nocturnal observations using infrared video. Proceedings of the $8^{\text {th }}$ International Coral Reef $443 \quad$ Symposium 2:1143-1148.

444 Houde E. 1989. Comparative growth, mortality, and energetics of marine fish larvae:

445 temperature and implied latitudinal effects. Marine Ecology Progress Series 87:471-495.

446 Houston AI, McNamara JM. 1999. Models of adaptive behaviour: an approach based on state.

447 Cambridge: Cambridge University Press.

448 Kacelnik A, El Mouden C. 2013. Triumphs and trials of the risk paradigm. Animal Behaviour $449 \quad 86: 1117-1129$.

450 Kacelnik A, Bateson M. 1996. Risky theories - the effects of variance on foraging decisions. $451 \quad$ American Zoologist 36:402-434.

452 Lim IS, Wittek P, Parkinson J. 2015. On the origin of risk-sensitivity: the energy budget rule 453 revisited. Animal Behaviour 110:69-77.

454 Miller T, Crowder L, Rice J, Marschall E. 1988. Larval size and recruitment mechanisms in 455 fishes: towards a conceptual framework. Canadian Journal of Fisheries and Aquatic Sciences $456 \quad 45: 1657-1670$.

457 R Development Core Team. 2018. R: a language and environment for statistical computing. R $458 \quad$ Foundation for Statistical Computing, Vienna, Austria.

459 Raimondi P. 1988. Settlement cues and determination of the vertical limit of an intertidal $460 \quad$ barnacle. Ecology 69:400-407.

461 Stamps JA, Krishnan VV, Reid ML. 2005. Search costs and habitat selection by dispersers. $462 \quad$ Ecology 86:510-518. 
463 Stamps JA. 2006. The silver spoon effect and habitat selection by natal dispersers. Ecology

$464 \quad$ Letters 9:1179-1185.

465 Stephens DW. 1981. The logic of risk-sensitive foraging preferences. Animal Behaviour 29:626$466 \quad 629$.

467 Smallwood PD. 1993. Web-site tenure in the long-jawed spider: is it risk-sensitive foraging, or 468 conspecific interactions? Ecology 74:1826-1835.

469 Smallwood PD. 1996. An introduction to risk sensitivity: the use of Jensen's inequality to clarify 470 evolutionary arguments of adaptation and constraint. American Zoologist 36:392-401.

471 Stier AC, Osenberg CW. 2010. Propagule redirection: habitat availability reduces colonization 472 and increases recruitment in reef fishes. Ecology 91:2826-2832.

473 Underwood AJ. 1999. Publication of so-called 'negative' results in marine ecology. Marine 474 Ecology Progress Series 191:307-209.

475 Victor BC. 1982. Daily otolith increments and recruitment in two coral-reef wrasses, 476 Thalassoma bifasciatum and Halichoeres bivittatus. Marine Biology 71:203-208.

477 Warner RR. 2001. Synthesis: environment, mating systems, and life history allocations in the 478 bluehead wrasse. In: Dugatkin LA, ed. Model systems in behavioral ecology: integrating 479 conceptual, theoretical, and empirical approaches. Princeton: Princeton University Press, $480 \quad 227-244$

481 White JW, Warner RR. 2007a. Safety in numbers and the spatial scaling of density-dependent 482 mortality in a coral reef fish. Ecology 88:3044-3054.

483 White JW, Warner RR. 2007b: Behavioral and energetic costs of group membership in a coral 484 reef fish. Oecologia $154: 423-433$.

485 Wickham, H. 2016: ggplot2 - Elegant graphics for data analysis. Springer-Verlag, New York. 


\section{Figure 1}

Relationships between different metrics of the number of copepods in guts of juvenile bluehead wrasse and group size (solitary fish have a group size of 1 ).

Each data point represents an individual group of fish or the sample of solitary fish on a particular reef and day. Each panel shows a different diet statistic: (a)mean number of copepods in guts within a group; (b) standard deviation of number of copepods within a group; (c) maximum number of copepods within a group. Lines indicate linear model fits (with group effect modeled as 1/[group size]) and shading indicates $95 \%$ confidence region around model fits. In (a, c), the first month (July 2012) is shown as triangle points, dashed curve and darker shading; circles, solid curve and lighter shading denotes the second month (August 2012). In (b), data are displayed as residuals with the effect of planktonic copepod abundance removed, and displayed according to site: Cane Bay (circles, solid curve, light shading), Northstar (triangles, dashed curve, medium shading), and Butler Bay (diamonds, dotted curve, dark shading). 
(a)

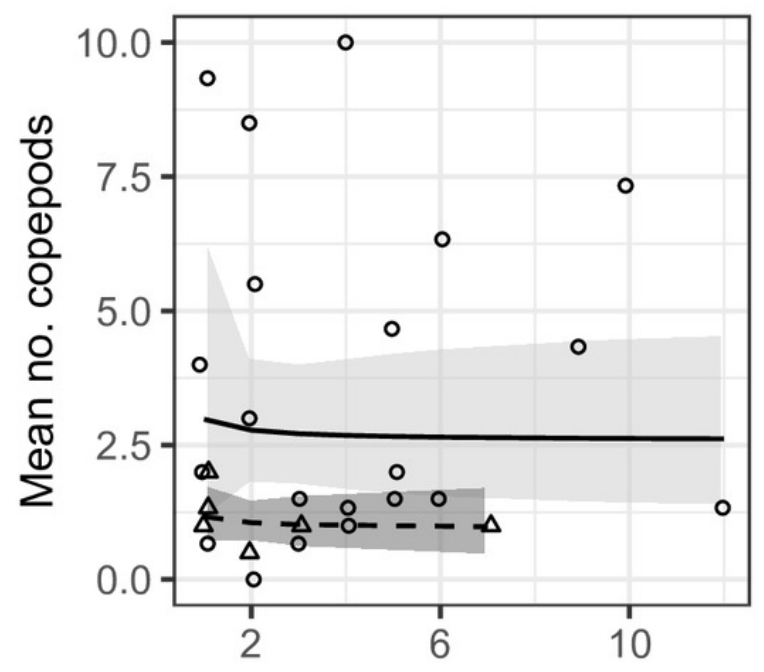

(b)

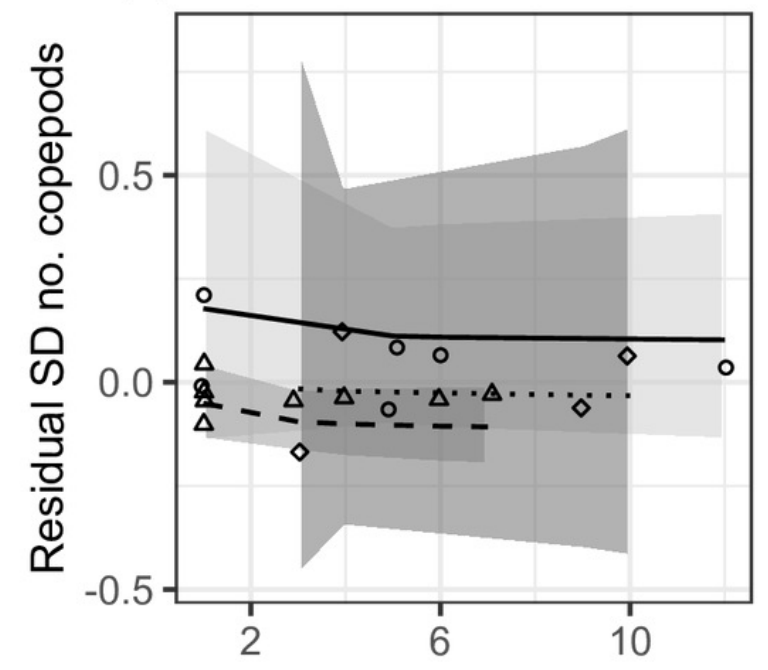

(c)

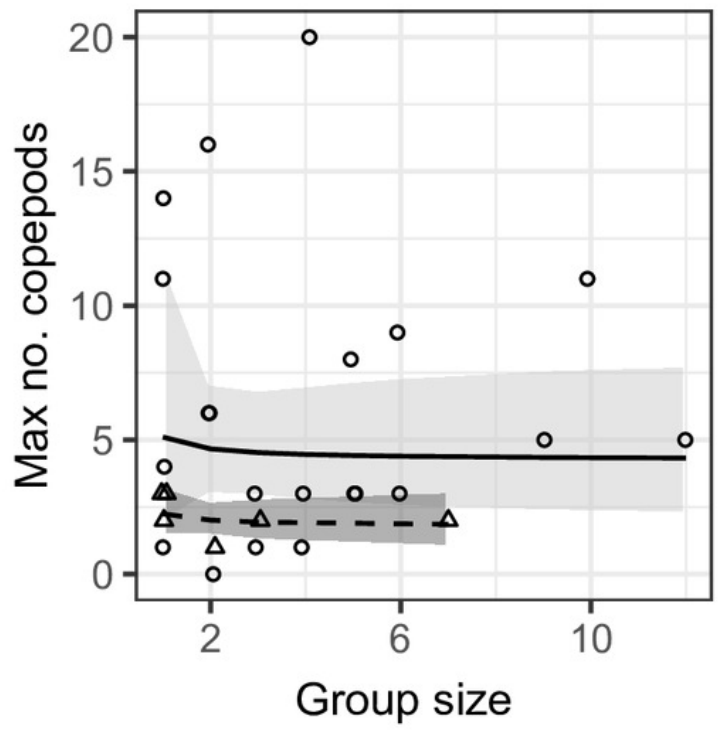

Peer] reviewing PDF | (2019:09:41367:1:0:NEW 20 Nov 2019) 


\section{Figure 2}

Relationships between different metrics of juvenile bluehead wrasse post-settlement growth rates (measured in otoliths) and group size.

Each data point represents an individual group of fish or the sample of solitary fish on a particular reef and day. Each panel shows a different growth rate statistic: (a)mean growth rate within a group; (b) standard deviation of growth rate within a group; (c) maximum growth rate within a group. Lines indicate linear model fits (with group effect modeled as 1/[group size]) and shading indicates $95 \%$ confidence region around model fits. In (a, c), the first month (July 2012) is shown as triangle points, dashed curve and darker shading; circles, solid curve and lighter shading denotes the second month (August 2012). In (b), data are displayed as residuals with the effect of planktonic copepod abundance removed, and displayed according to site: Cane Bay (circles, solid curve, light shading), Northstar (triangles, dashed curve, medium shading), and Butler Bay (diamonds, dotted curve, dark shading). 
(a)

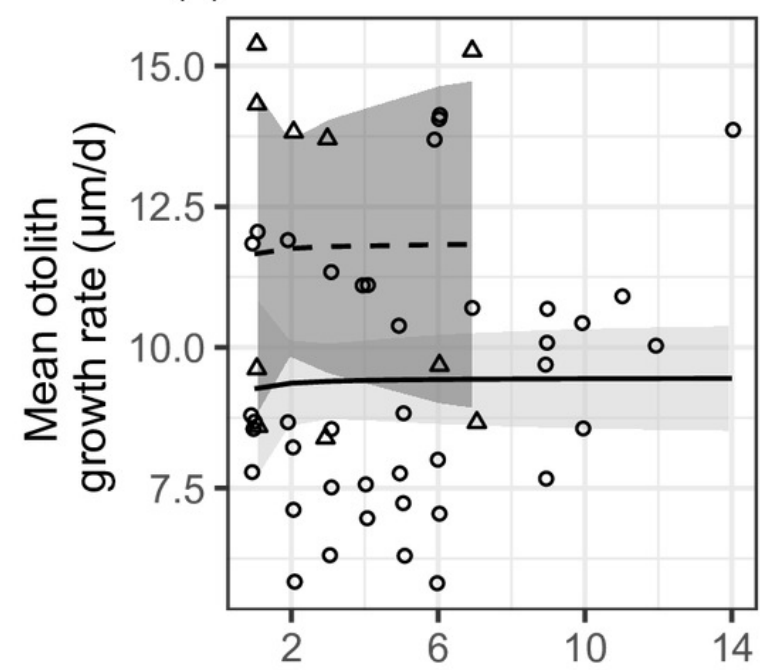

(b)

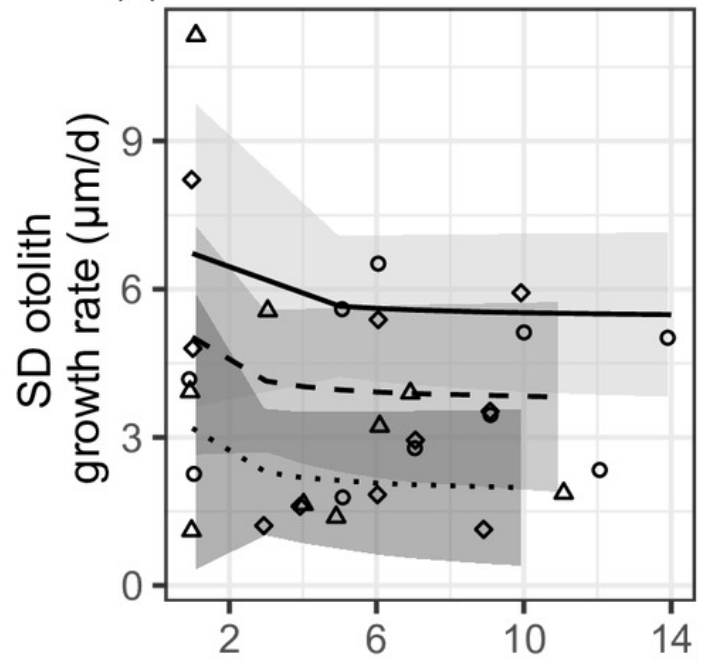

(c)

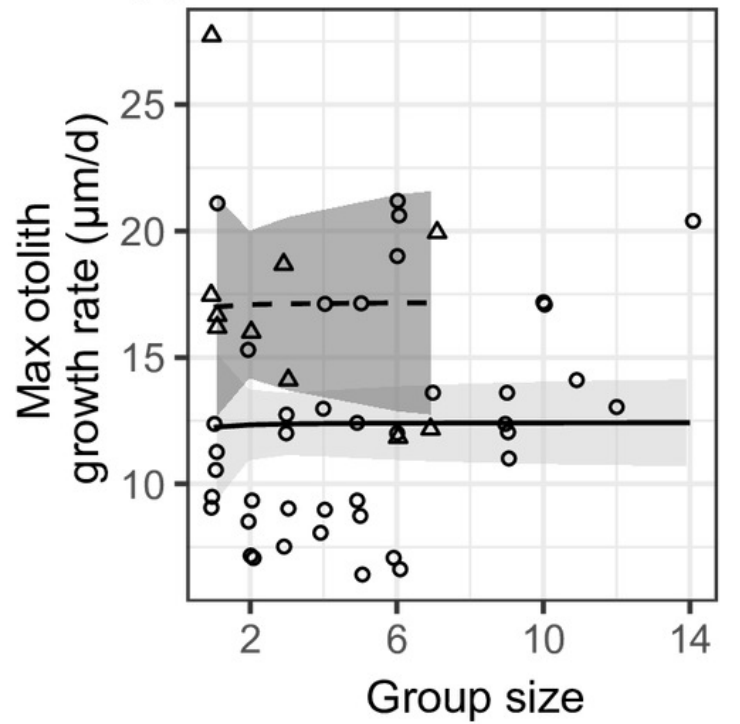

